\title{
Target Zone Interventions and Coordination of Expectations*
}

\author{
Stefan Reitz, University of Giessen, Department of Economics
}

Frank Westerhoff**, University of Osnabrueck, Department of Economics

Cristian Wieland, Raad Consult, Münster

\begin{abstract}
Foreign exchange markets regularly display severe bubbles. This paper explores whether or not so-called target zone interventions are an effective tool for central banks to stabilize the exchange rate. We define such intervention operations as buying/selling an undervalued/overvalued currency when the distance between the exchange rate and its fundamental value exceeds a critical threshold value. On the basis of a non-linear empirical exchange rate model with chartists and fundamentalists, we find that target zone interventions not only have the power to reduce misalignments but also earn profits.
\end{abstract}

\section{Keywords}

foreign exchange markets, technical and fundamental analysis, heterogeneous agents, central bank intervention, target zone

\section{JEL classification}

D84, E58, F31

\footnotetext{
* The idea of this paper was born during the Complexity 2003 Workshop in Aix-en-Provence and the $8^{\text {th }}$ Viennese Workshop on Optimal Control, Dynamic Games and Nonlinear Dynamics, May 2003. We thank Richard Day, Herbert Dawid, Cars Hommes, Erik Mosekilde, Barkley Rosser and Jan Tuinstra for their stimulating discussions. We also thank seminar participants at the University of Kiel, especially Thomas Lux, for helpful comments.

** Contact: Frank Westerhoff, University of Osnabrueck, Department of Economics, Rolandstrasse 8, D-49069 Osnabrueck, Germany. Email: fwesterho@oec.uni-osnabrueck.de.
} 


\section{Introduction}

Since exchange rates directly affect international competitiveness and the performance of national economies, they are arguably the world economy's most important prices. Unfortunately, foreign exchange markets do not seem to be very efficient. For example, Johansen and Sornette (2003) detect significant bubbles and crashes in the DEM/USD and JPY/USD market. It is therefore not surprising that central banks try to stabilize foreign exchange markets. However, the empirical evidence is ambivalent about the usefulness of intervention operations (Neely 2001). The aim of this paper is to examine this issue from a theoretical perspective.

In a number of studies by, e.g., Day and Huang (1990), Kirman (1991), de Grauwe, Dewachter and Embrechts (1993), Brock and Hommes (1998), LeBaron, Arthur and Palmer (1999), Lux and Marchesi (2000), Farmer and Joshi (2002), Chiarella and He (2002), or Chiarella, Dieci and Gardini (2003) it is argued that financial market dynamics is mainly driven by the interaction between heterogeneous agents, so-called chartists and fundamentalists. As vividly expressed by Hommes (2001), financial markets may be viewed as evolutionary systems between different competing trading strategies. Strategies that have performed well in the past have a higher market impact than their worse performing competitors. As it turns out, technical and fundamental trading rules may coexist in speculative markets, implying that technical analysis may survive natural selection pressure. Intricate price dynamics arise due to the fact that the impact of the trading strategies changes endogenously over time. For instance, if the popularity of fundamentalism decreases, bubbles are likely to occur.

Wieland and Westerhoff (2004) thus explore whether chaos control methods may help central banks to stabilize exchange rate dynamics. Using the prototype nonlinear chartist-fundamentalist model of Day and Huang (1990) they find that certain 
control algorithms such as the OGY method, named after Ott, Grebogi and Yorke (1990), indeed have the power to reduce exchange rate variability and misalignments, even if the dynamics is considerably polluted by noise. Interestingly, some of these algorithms are related to actual central bank intervention rules: The OGY method may be interpreted as a more sophisticated version of the "targeting long-run fundamentals rule", which is often carried out by central banks (Neely 2001).

The study by Wieland and Westerhoff (2004) should be regarded as preliminary, since several interesting aspects remain open. First, to conduct chaos control methods, one typically needs a priori knowledge on the system's equations. Such information may in general be retrieved from time series information, yet in the case of foreign exchange markets, this requirement appears to be rather hard. Second, the derived intervention rules basically suggest intervening every period (i.e. every day). But policy makers may not want to manipulate the exchange rate so regularly. As reported by LeBaron (1999) and Saacke (2002), the Federal Reserve Bank and the Bundesbank intervened together in the DEM/USD market in the period between 1979 and 1996 in one day in four. At other times, they were not active so often. Third, the parameters of the exchange rate's law of motion have been set such that it can mimic characteristic bull and bear markets. Although this is a common procedure, the results would be more reliable if the parameters were directly estimated from empirical data.

In this paper, we seek to address these three issues by investigating the effectiveness of a robust low-frequency intervention heuristic within an empirical exchange rate model recently developed by Westerhoff and Reitz (2003). The main engine of the dynamics of their chartist-fundamentalist setup is that fundamentalists become less active the more the exchange rate disconnects from its fundamental value. The underlying intuition is that fundamentalists lose confidence in their strategy when 
they have mispredicted the direction of the exchange rate change. The structure of the model is backed up by the data: Via a STAR GARCH procedure, significant parameter estimates with correct signs are derived for major currencies vis-à-vis the US dollar.

This paper focuses on target zone interventions which imply buying/selling an undervalued/overvalued currency when the distance between the exchange rate and its fundamental value exceeds a critical threshold value. To make the rule as simple and robust as possible, we fix the central bank's actual per period intervention volume. Note that this mechanism is different from the historical European currency system. There the authorities have stopped the exchange rate from leaving a certain exchange rate band. In our model, interventions start when the exchange rate leaves a specified target zone. Within the band, the central bank is indifferent to the path of the exchange rate.

We find that intermittent target zone interventions apparently suffice to reduce misalignments in foreign exchange markets. Suppose the central bank sets a target zone of \pm 8 percent around the fundamental value. Taking our estimates literally, the model predicts the following: To reduce the distortion by about 50 percent, the central bank has to intervene on average only every 40 trading days. In addition, the intervention strategy seems to be profitable. By buying low and selling high, the relation of profits to the total intervention volume is close to 10 percent. The intervention works as follows: It directly shifts the exchange rate towards its fundamental value, chartists amplify this new exchange rate trend, and more fundamentalists are encouraged to become active. By coordinating the behavior of chartists and fundamentalists, the temporary intervention effect is likely to become a permanent one.

The paper is organized as follows. In section 2, we briefly recall the empirical exchange rate model of Westerhoff and Reitz (2003) and in section 3, we explore the effectiveness of target zone interventions. The final section concludes the paper. 


\section{A simple empirical chartist-fundamentalist model}

\subsection{Motivation}

The chartist-fundamentalist approach is based on the observation that financial market participants use simple technical and fundamental trading strategies to take their investment decisions (Frankel and Froot 1987). While technical analysis identifies trading signals out of past price movements, fundamental analysis predicts prices to return to fundamentals. The nature of technical analysis tends to be destabilizing whereas the nature of fundamental analysis is stabilizing. The interplay between positive and negative feedback rules may cause complex price dynamics. Some studies exploit the nonlinearity of the agents' trading rules (e.g. Day and Huang 1990). Within other contributions the market impact of the rules changes over time (e.g. Brock and Hommes 1998). The fact that these models are able to replicate the stylized facts of financial markets quite well is seen as a kind of empirical validation.

Let us briefly review the model of Westerhoff and Reitz (2003). The exchange rate adjusts via a log-linear price impact function: Excess buying drives the exchange rate up, and excess selling drives it down. The orders of chartists positively depend on the most recent exchange rate trend and the demand of fundamentalists is proportional to the mispricing. A constant number of chartists is always active in the market, but the market impact of fundamentalists is time-dependent. Most importantly, if the exchange rate disconnects from its fundamental value, fundamentalists lose their confidence in the usefulness of their trading rule and consequently abstain from trading. If misalignments decrease, as predicted by fundamental analysis, they re-enter the market. Misalignments are furthermore conditioned on volatility. Without fluctuations, convergence is not possible. Hence, if exchange rate volatility declines, fundamentalists expect mean reversion to be less likely. 
Estimations based on daily data for major currencies indeed reveal that the more the exchange rate deviates from its fundamental value, the more fundamentalists leave the market. The model indicates that foreign exchange markets become increasingly unstable during bubbles. The diminishing force of fundamentalists alone may therefore not suffice to bring exchange rates back in line. A natural question which arises is whether central bank interventions may help to deflate bubbles.

\subsection{Setup}

The model is estimated via a STAR GARCH procedure developed by Lundbergh and Teräsvirta (1998). In technical terms, the model consists of a mean equation, a smooth transition variable and a standard $\operatorname{GARCH}(1,1)$ volatility equation

$$
\begin{aligned}
& S_{t}-S_{t-1}=a^{C}\left(S_{t-1}-S_{t-2}\right)+a^{F}\left(F_{t-1}-S_{t-1}\right) W_{t-1}+\varepsilon_{t}, \\
& W_{t}=\frac{2 \operatorname{Exp}\left[-b\left|F_{t}-S_{t}\right| / \sqrt{H_{t}}\right]}{1+\operatorname{Exp}\left[-b\left|F_{t}-S_{t}\right| / \sqrt{H_{t}}\right]},
\end{aligned}
$$

and

$$
H_{t}=c^{1}+c^{2} \varepsilon_{t-1}^{2}+c^{3} H_{t-1},
$$

with $\varepsilon_{t}=v_{t} \sqrt{H_{t}}$ and $v_{t}^{i i d} \sim N(0,1)$. According to (1), the change in the log exchange rate $S$ depends on the orders of chartists (first term), the orders of fundamentalists (second term) and a random element (third term). $a^{C}$ and $a^{F}$ stand for positive reaction coefficients of chartists and fundamentalists, respectively. The fundamental value is denoted by $F$. The transition variable $W$ takes into account that the impact of fundamentalists diminishes with increasing misalignments and decreasing volatility. A simple GARCH $(1,1)$ model is used to update the volatility. 


\subsection{Estimation results}

The fundamental value is approximated by the purchasing power parity (henceforth ppp). For daily spot DEM/USD exchange rates over the period from 1980 to 1996 the model's parameters are estimated as follows:

${ }_{a}^{C}=0.03, a^{F}=0.004, b=0.035, c^{1}=0.0000011, c^{2}=0.069, c^{3}=0.909$.

All coefficients are of the correct sign and statistically significant, at least at the 5 percent level. Similar results are obtained for GBP/USD and JPY/USD exchange rates (see Westerhoff and Reitz 2003 for more details).

Figure 1 illustrates the working of the model. The first panel displays daily log DEM/USD exchange rates (solid line) and ppp data (dashed line). Both time series are normalized to zero at 1990, assuming that ppp holds at the beginning of the 1990s. The second panel shows the estimated impact of fundamentalists. The lasting US dollar bubble in the mid 1980s is accompanied by a deep fall in confidence in fundamental analysis. In particular, the impact of fundamentalists dropped below 10 percent when the dollar peaked in mid 1985. The third panel depicts the evolution of changes in log exchange rates (i.e. the returns). Periods of low volatility clearly alternate with periods of high volatility, which is typical for financial markets (Lux and Ausloos 2002).

-------- Figure 1 goes about here ---------

Using (1) - (3) and the above parameters, we can, of course, produce artificial time series. Figure 2 contains a simulation run over 5000 observations. The first, second and third panels again present log exchange rates, weights of fundamentalists and returns, respectively. For simplicity, we have set the fundamental value constant $(F=0)$. The dynamics in figure 2 resembles the dynamics in figure 1. For instance, the exchange rate circles in a complex way around its fundamental value and bubble periods coincide with periods in which fundamental analysis is unpopular. Exactly 
when the stabilizing impact of fundamentalists is most needed, mean reversion pressure is low so that the mispricing may gain additional momentum. The bottom panel reveals that the model has the potential to produce volatility clustering. Further diagnostic tests also confirm that the returns are serially uncorrelated and that the distribution of the returns is non-normal, i.e. it possesses fat tails.

Figure 2 goes about here

\section{Target zone interventions}

\subsection{Specification}

The previous section suggests that foreign exchange markets are inherently unstable. Bubbles may not end endogenously but may need external force such as random trade or new information. Such external stimulus may also be injected by central banks. Next, we try to present a simple robust low-frequency intervention method suitable for this task. So-called target zone interventions may be written as

$$
D_{t}^{C B}=\left\{\begin{aligned}
+d & \text { for } \quad F_{t}-S_{t}>e \\
-d & \text { for } \quad S_{t}-F_{t}>e \\
0 & \text { otherwise }
\end{aligned}\right.
$$

where $d$ is a fixed intervention size and $e$ defines the range of the target zone. Suppose, for instance, that $e=0.2$. Then policy makers do not intervene as long as the distance between the exchange rate and its fundamental value is lower than 20 percent. If the exchange rate is misaligned more than 20 percent, then they either sell $(S>F)$ or buy foreign currency $(S<F)$. The intervention variable $D_{t-1}^{C B}$ is added to the right-hand side of (1), else the system remains as before.

We measure the success of this method with the help of four statistics. The distortion in the market is computed as the average absolute distance between the log 
exchange rate and its log fundamental value

distortion $=\frac{1}{T} \sum_{t=1}^{T}\left|S_{t}-F_{t}\right|$,

where $T$ is the sample length. The profitability of intervention operations is calculated as

$$
\text { profit }=S_{T+1} \sum_{t=1}^{T} D_{t}^{C B}-\sum_{t=1}^{T} S_{t} D_{t}^{C B}
$$

The first term of (6) captures what the accumulated position of the central bank is worth after period $T$ while the second term keeps track of the gains and losses due to individual interventions. The frequency of intervention is just given as the number of intervention days divided by the number of trading days

frequency $=\frac{1}{T} \sum_{t=1}^{T} I_{t}$,

where $I_{t}=1$ for $D_{t}^{C B} \neq 0$ and $I_{t}=0$ for $D_{t}^{C B}=0$. The total amount of interventions is simply the sum over all single interventions

$$
\text { amount }=\sum_{t=1}^{T}\left|D_{t}^{C B}\right| \text {. }
$$

An important goal of the central bank should be to reduce distortion. In addition, the central bank may also look at the profits, the frequency and the total amount of intervention operations.

\subsection{Example}

Let us start the analysis by inspecting an example. The first, second and third panels of figure 3 show a simulation run of log exchange rates, weights of fundamentalists and target zone interventions, respectively. Figure 3 can be directly compared with figure 2 
since it is based on the same seed of random variables. The difference in the dynamics is solely a result of the behavior of the central bank. The interventions are carried out with strength $d=0.01$ when the distance between the log exchange rate and its log fundamental value exceeds $e=0.08$.

The results are remarkable. The exchange rate now fluctuates much closer to its fundamental value, although the central bank trades only once in a while. In numerical terms, the distortion decreases from about 0.084 to 0.037 . The central bank becomes active 125 times in 5000 periods (i.e. in 2.5 percent of the trading days). Moreover, the interventions are profitable and the central bank's net position appears rather balanced.

The method works as follows. The intervention has a direct effect on the course of the exchange rate, i.e. it pushes the exchange rate towards its fundamental value. By inducing such a trend, additional orders of chartists are triggered which further guide the exchange rate back towards its fundamental value. In addition, the confidence of fundamentalists in their trading strategy increases, i.e. more stabilizing fundamentalists are active on average (see the central panel of figure 3). Note that whenever the exchange rate converges towards it fundamental value, both chartists and fundamentalists trade in the same direction. One may thus say that target zone interventions help coordinate the expectations of heterogeneous agents.

-------- Figure 3 goes about here

Note that coordinated behavior may lead to stronger exchange rate changes. However, the exchange rate moves in the direction of the fundamental value. Such a volatility-enhancing strategy may clearly be intended by central banks (for an empirical account see Hung 1997). But it makes sense to halt this mechanism for two reasons. First, the central bank may not want to manipulate the exchange rate in every period. Second, coordination of chartists and fundamentalists close to the fundamental value is 
prevented. The central banks may take care of these issues by selecting an appropiate target zone.

\subsection{A Monte Carlo analysis}

To evaluate the success of target zone interventions, a more general kind of analysis is needed. Figure 4 shows how the statistics react to an increase in the intervention size. All estimates are computed as averages over 10 simulation runs with 5000 observations each. The intervention size $d$ is increased in 20 discrete steps from 0 to 0.01 . The target zone is $e=0.08$ and the remaining parameters are as in section 3.2.

Target zone interventions are in fact a powerful instrument to stabilize foreign exchange markets. For an intervention size of $d=0.01$, the distortion is reduced by around 50 percent, although the policy makers only trade in about 2.5 percent of the cases. Moreover, interventions earn profits. Compared to the total amount of intervention, they may be as large as 10 percent. Our study also suggests that when central authorities decide to intervene, they should do it rather forcefully. If the intervention size is low, they have to intervene much more frequently, yet the outcome is still not as good.

\section{----- Figure 4 goes about here -------}

Are these results robust with respect to different target zones? Figures 5 and 6 display the findings for bands with $e=0.04$ and $e=0.12$, respectively. Overall, the results are qualitatively the same as in figure 4 . We again see a reduction in the distortion and positive profits. However, the smaller the target zone, the lower the distortion, and the higher the profits, but also the more frequent the interventions. For instance, for $e=0.04$ and $d=0.01$, the central bank intervenes on average every 17 periods and thereby drives the distortion down to 2 percent. 
A final comment seems to be in order. Our results are apparently not far away from what some central banks have done in the past. Inspecting actual intervention data from the Federal Reserve Bank and the Bundesbank, LeBaron (1999) and Saacke (2002) conclude that the interventions produced profits. Neely (2001), who conducted a survey study among monetary authorities regarding their intervention practice in the 1990s, concludes that interventions are quite common in foreign exchange markets. The percentage of business days on which they report having intervened, ranged from 0.5 percent to 40 percent, with 4.5 percent being the median. In addition, policy makers indicated that they seek to return the exchange rate to fundamental values.

\section{Conclusions}

Can central bank interventions control the cyclical behavior of exchange rates? Using an empirical chartist-fundamentalist exchange rate model in which the market impact of fundamentalists depends on the strength of their belief in fundamental analysis, we find that low-frequency target zone interventions are not only profitable but also manage to reduce distortions considerably. Such an intervention is executed when the exchange rate leaves a pre-specified band around the fundamental value and works as follows. It directly drives the exchange rate towards its fundamental value, the new exchange rate trend is amplified by chartists, and fundamentalists are encouraged to take larger positions. In other words, the stabilizing direct effect of the intervention is amplified and prolonged since it stimulates additional uniform trades of chartists and fundamentalists.

\footnotetext{
${ }^{1}$ Given the evidence presented here, it is surprising that the European Central Bank has remained quite inactive since the launch of the Euro, especially with respect to the Euro's extreme cyclical course.
} 


\section{References}

Brock, W. and Hommes, C. (1998): Heterogeneous beliefs and routes to chaos in a simple asset pricing model. Journal of Economic Dynamics and Control, 22, 12351274.

Chiarella, C. and He, X. (2002): Asset pricing and wealth dynamics under heterogeneous expectations. Quantitative Finance, 1, 509-526.

Chiarella, C., Dieci, R. and Gardini, L. (2003): The dynamic interaction of speculation and diversification. University of Technology Sydney, School of Finance and Economics, Working paper.

Day, R. and Huang, W. (1990): Bulls, bears and market sheep. Journal of Economic Behavior and Organization, 14, 299-329.

De Grauwe, P., Dewachter, H. and Embrechts, M. (1993): Exchange rate theory chaotic models of foreign exchange markets. Blackwell: Oxford.

Farmer, D. and Joshi, S. (2002): The price dynamics of common trading strategies. Journal of Economic Behavior and Organization, 49, 149-171.

Frankel, J. and Froot, K. (1987): Using survey data to test standard propositions regarding exchange rate expectations. American Economic Review, 77, 133-153.

Hommes, C. (2001): Financial markets as nonlinear adaptive evolutionary systems. Quantitative Finance, 1, 149-167.

Hung, J. (1997): Intervention strategies and exchange rate volatility: a noise trading perspective. Journal of International Money and Finance, 16, 779-793.

Johansen, A. and Sornette, D. (2003): Endogenous versus exogenous crashes in financial markets. Journal of Economic Dynamics and Control (in press).

Kirman, A. (1991): Epidemics of opinion and speculative bubbles in financial markets. In: Taylor, M. (Ed.): Money and Financial Markets. Blackwell: Oxford, 354-368. 
LeBaron, B. (1999): Technical trading rule profitability and foreign exchange intervention. Journal of International Economics, 49, 125-143.

LeBaron, B., Arthur, B. and Palmer, R. (1999): Time series properties of an artificial stock market. Journal of Economic Dynamics and Control, 23, 1487-1516.

Lundbergh, S. and Teräsvirta, T. (1998): Modeling economic high frequency time series with STAR GARCH models. Stockholm School of Economics, Working paper 291.

Lux, T. and Marchesi, M. (2000): Volatility clustering in financial markets: a microsimulation of interacting agents. International Journal of Theoretical and Applied Finance, 3, 675-702.

Lux, T. and Ausloos, M. (2002): Market fluctuations I: Scaling, multiscaling, and their possible origins. In: Bunde, A., Kropp, J. and Schellnhuber, H. (Eds.): Science of Disaster: Climate Disruptions, Heart Attacks, and Market Crashes. Springer, Berlin, 373-410.

Neely, C. (2001): The practice of central bank intervention: Looking under the hood. Federal Reserve Bank of St. Louis Review, 83, 1-10.

Ott, E., Grebogi, C. and Yorke, J. (1990): Controlling chaos. Physical Review Letters, 64, 1196-1199.

Saacke, P. (2002): Technical analysis and the effectiveness of central bank intervention. Journal of International Money and Finance, 21, 459-479

Westerhoff, F. and Reitz, S. (2003): Nonlinearities and cyclical behavior: The role of chartists and fundamentalists. Studies in Nonlinear Dynamics and Econometrics, 7/4, Article 3.

Wieland C. and Westerhoff, F. (2004): Exchange rate dynamics, central bank interventions and chaos control methods. Journal of Economic Behavior and Organization (in press). 

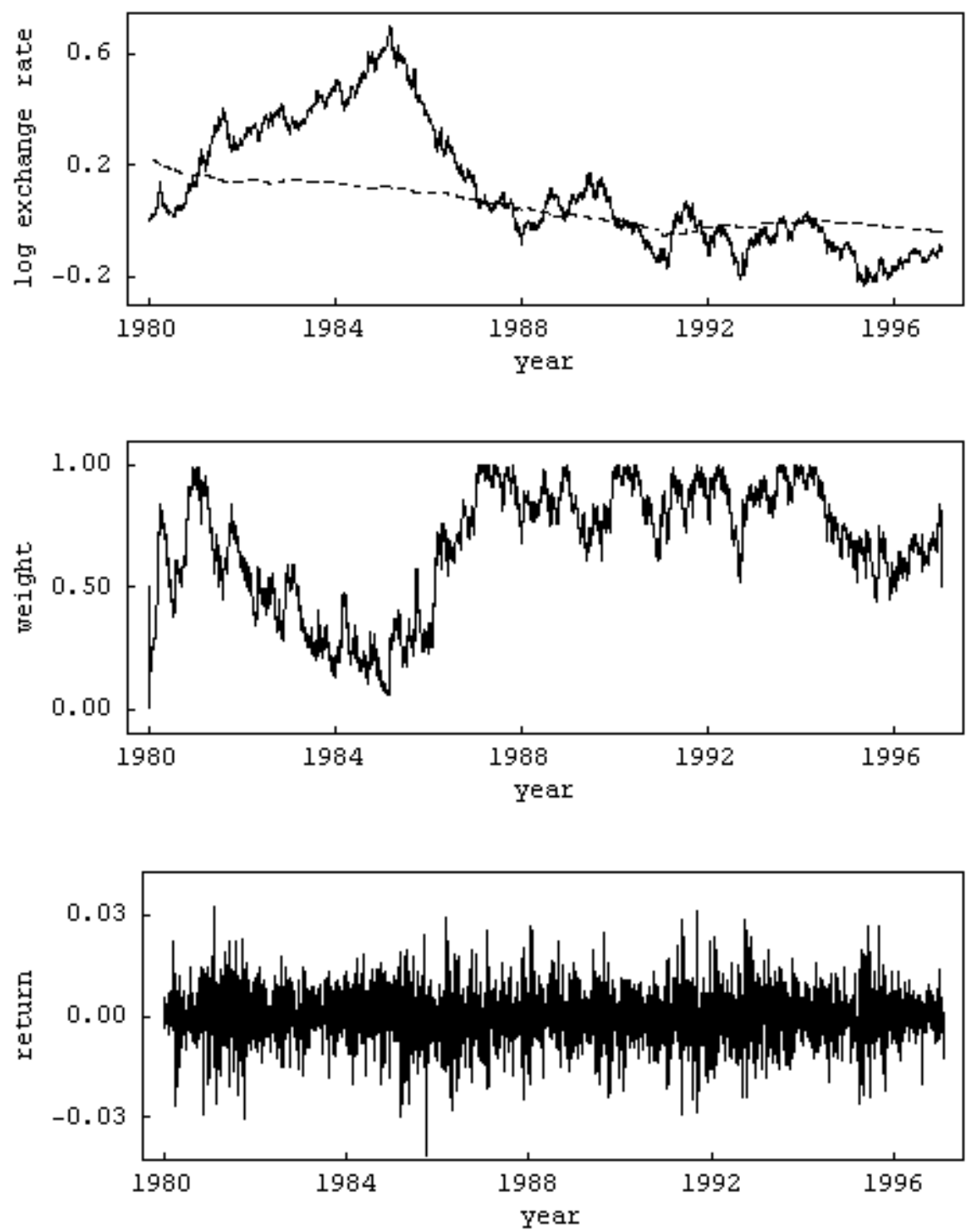

Figure 1: The first panel displays daily log DEM/USD exchange rates (solid line) and ppp data (dashed line) for the period 1980-1996. Both time series are normalized to zero at 1990, assuming that ppp holds at the beginning of the 1990s. The second panel shows the estimated weights of the fundamentalists, whereas the third panel depicts the evolution of the returns. 

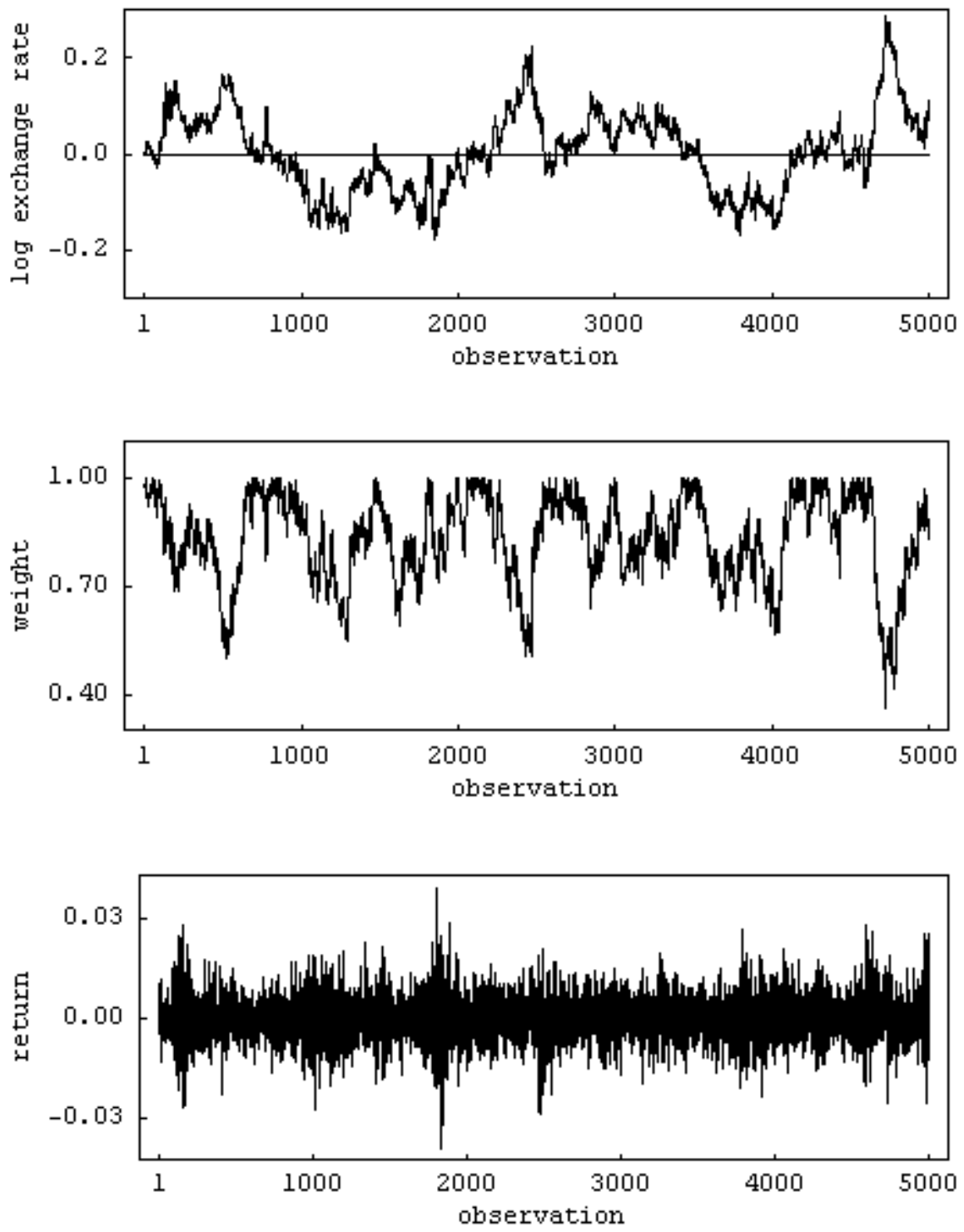

Figure 2: The first, second and third panels present a simulation run of log exchange rates, weights of fundamentalists and returns, respectively. The parameter setting is as in section 3.2, 5000 observations. 

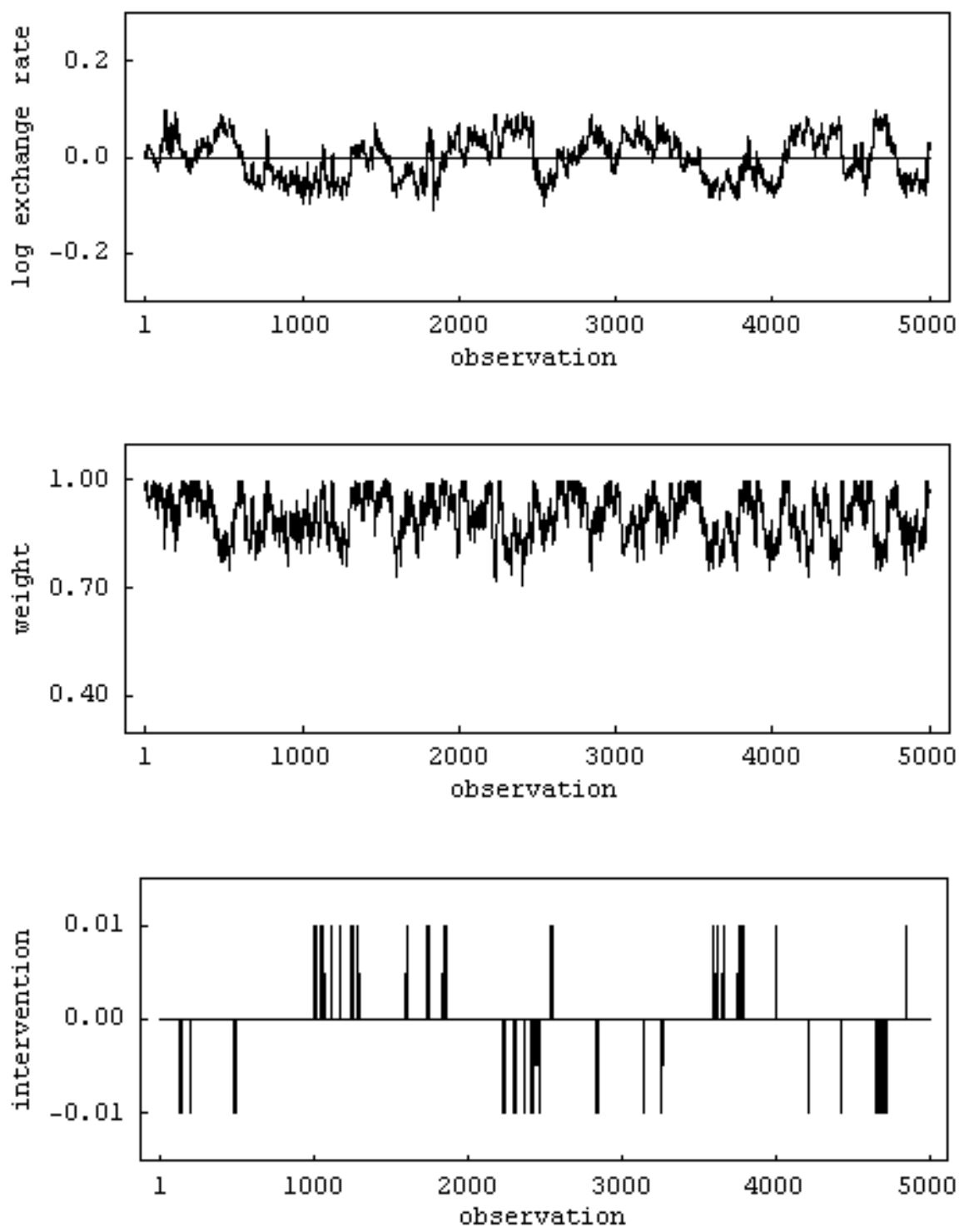

Figure 3: The first, second and third panels show a simulation run of log exchange rates, weights of fundamentalists and target zone interventions, respectively. The same simulation design is used as in figure 2 , but $d=0.01$ and $e=0.08$ 

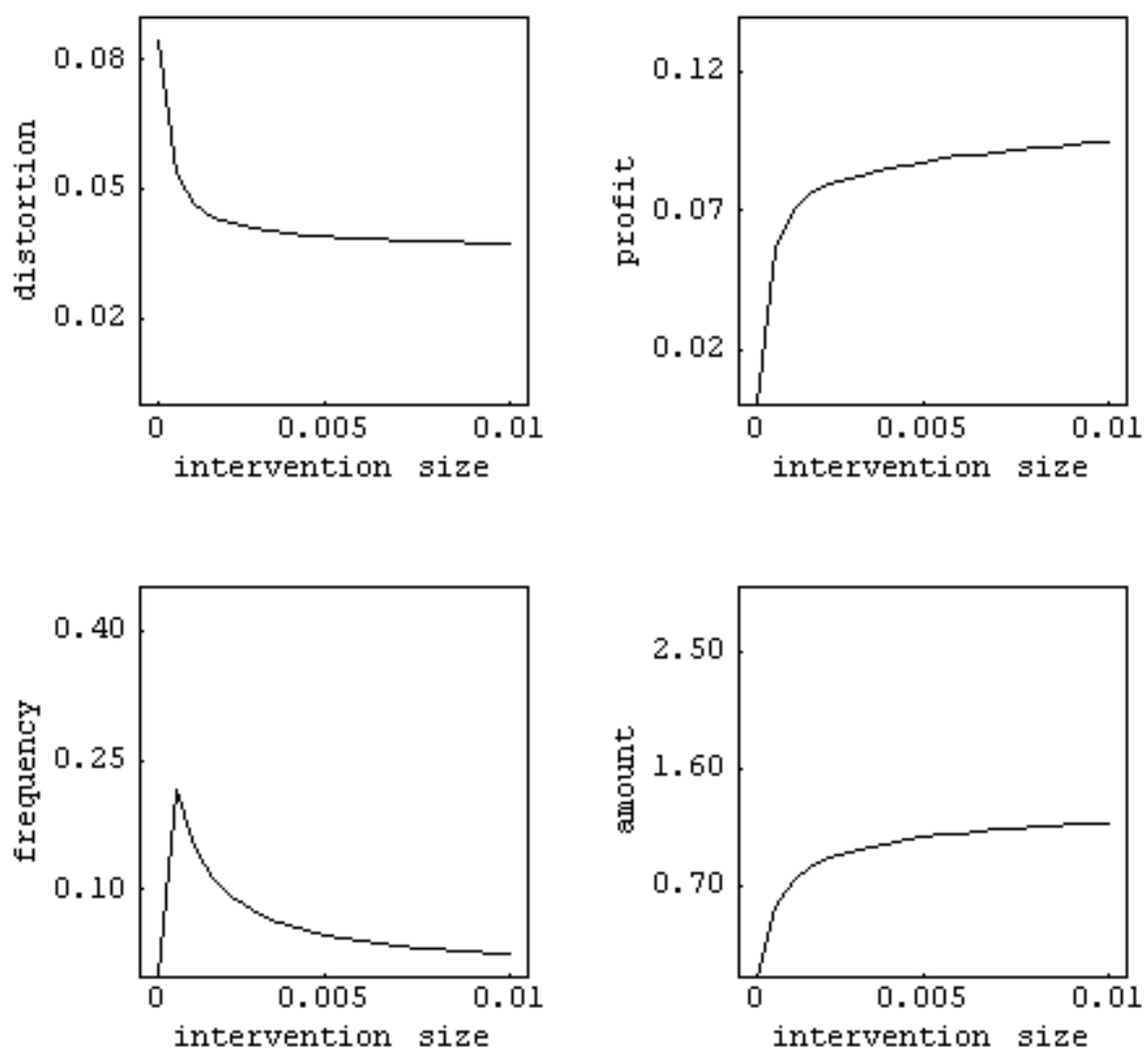

Figure 4: The four panels reveal the impact of increasing intervention sizes $d$ on the distortion, the profitability of interventions, the frequency of interventions, and the total amount of interventions, respectively. All estimates are averages over 10 simulation runs with 5000 observations each. The intervention size $d$ is increased in 20 discrete steps from 0 to 0.01 . The target zone is $e=0.08$. The remaining parameters are as in section 3.2. 

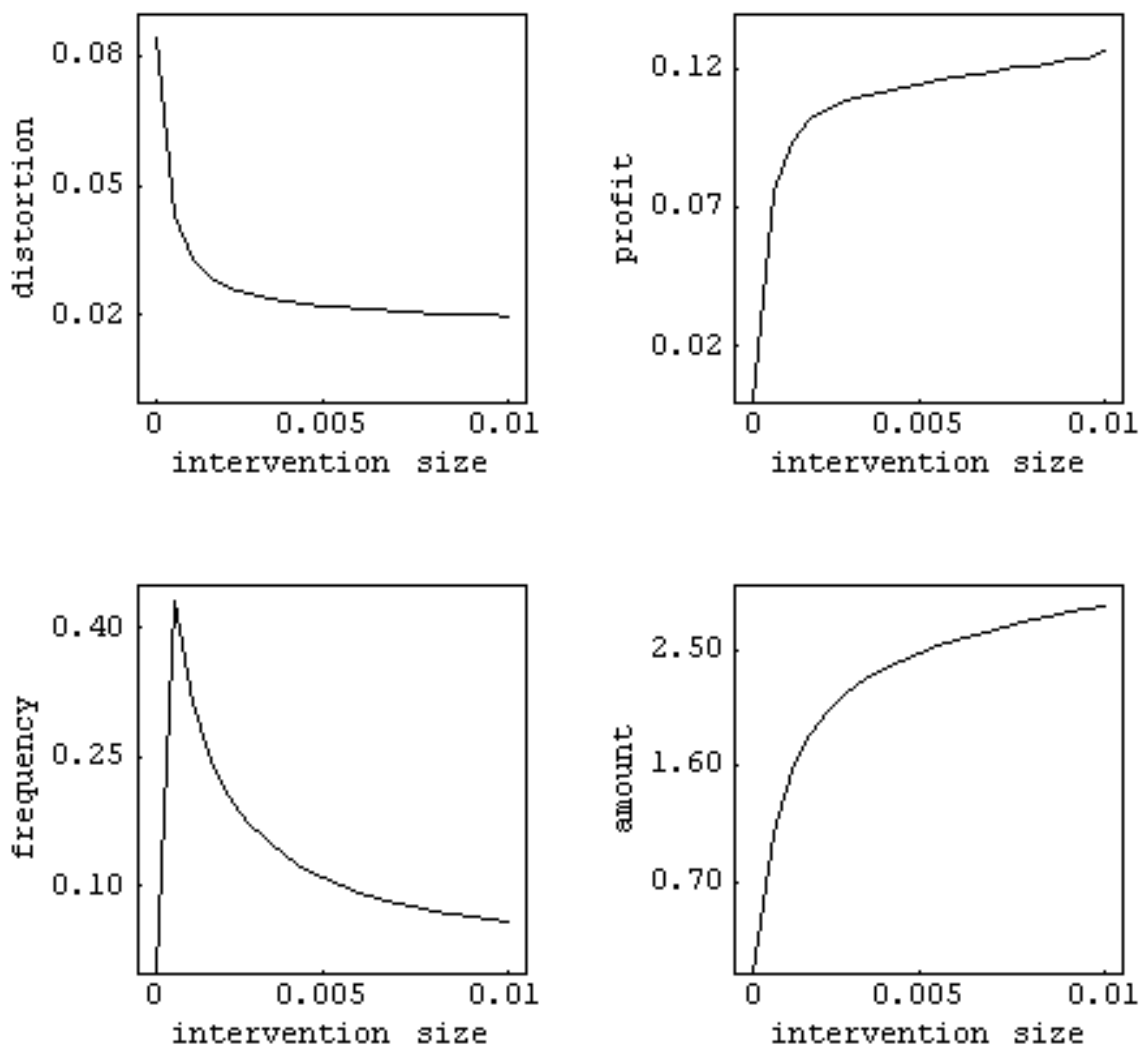

Figure 5: The four panels reveal the impact of increasing intervention sizes $d$ on the distortion, the profitability of interventions, the frequency of interventions, and the total amount of interventions, respectively. The same simulation design is used as in figure 2 , but now $e=0.04$. 

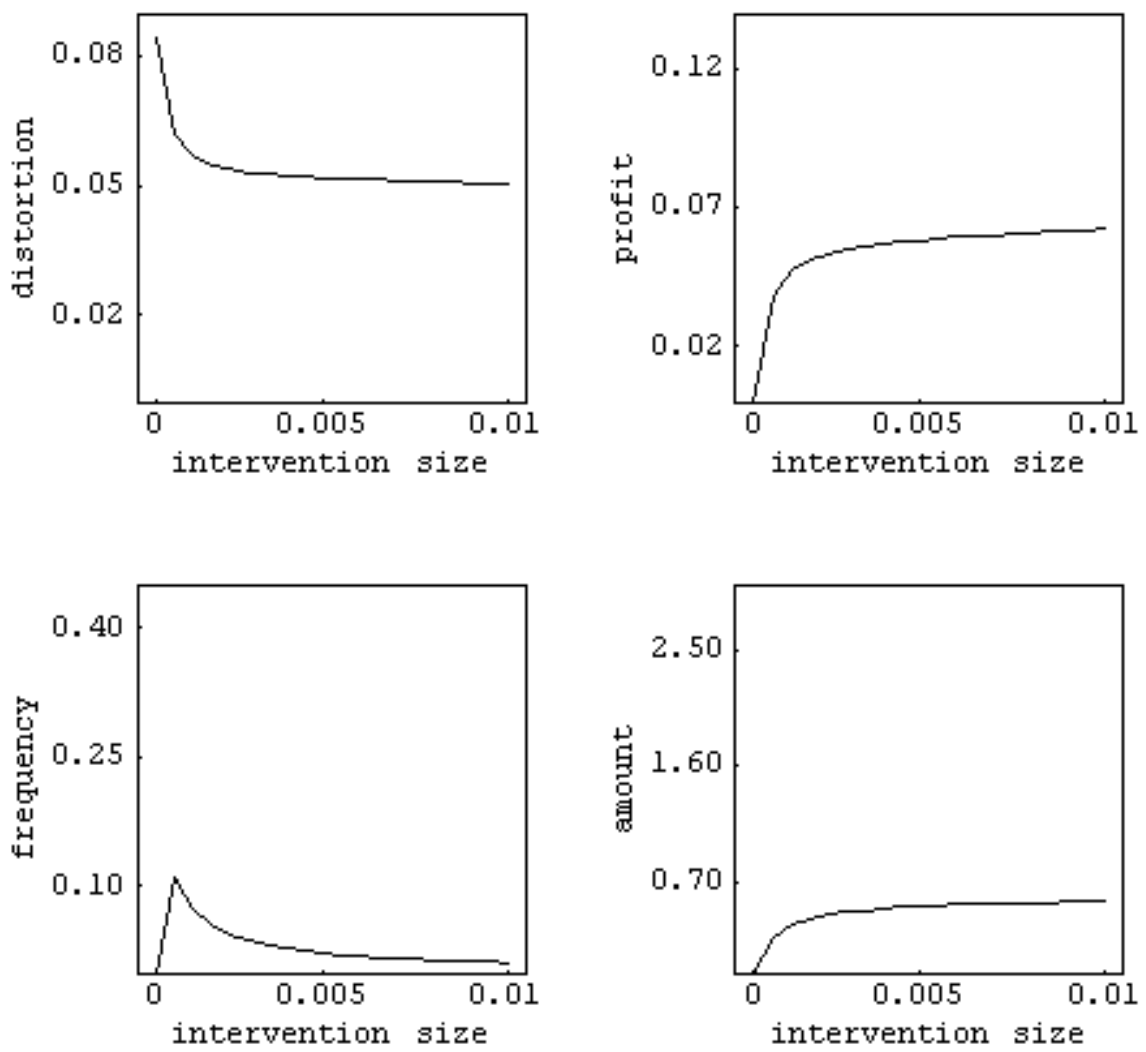

Figure 6: The four panels reveal the impact of increasing intervention sizes $d$ on the distortion, the profitability of interventions, the frequency of interventions, and the total amount of interventions, respectively. The same simulation design is used as in figure 2 , but now $e=0.12$. 